\title{
SAFOD Penetrates the San Andreas Fault
}

SAFOD, the San Andreas Fault Observatory at Depth (Fig. 1), completed an important milestone in July 2005 by drilling through the San Andreas Fault at seismogenic depth. SAFOD is one of three major components of EarthScope, a U.S. National Science Foundation (NSF) initiative being conducted in collaboration with the U.S. Geological Survey (USGS). The International Continental Scientific Drilling Program (ICDP) provides engineering and technical support for the project as well as online access to project data and information (http://www.icdp-online.de/sites/sanandreas/ news/news1.html). In 2002, the ICDP, the NSF, and the USGS provided funding for a pilot hole project at the SAFOD site. Twenty scientific papers summarizing the results of the pilot hole project as well as pre-SAFOD site characterization studies were published in Geophysical Research Letters (Vol. 31, Nos. 12 and 15, 2004).

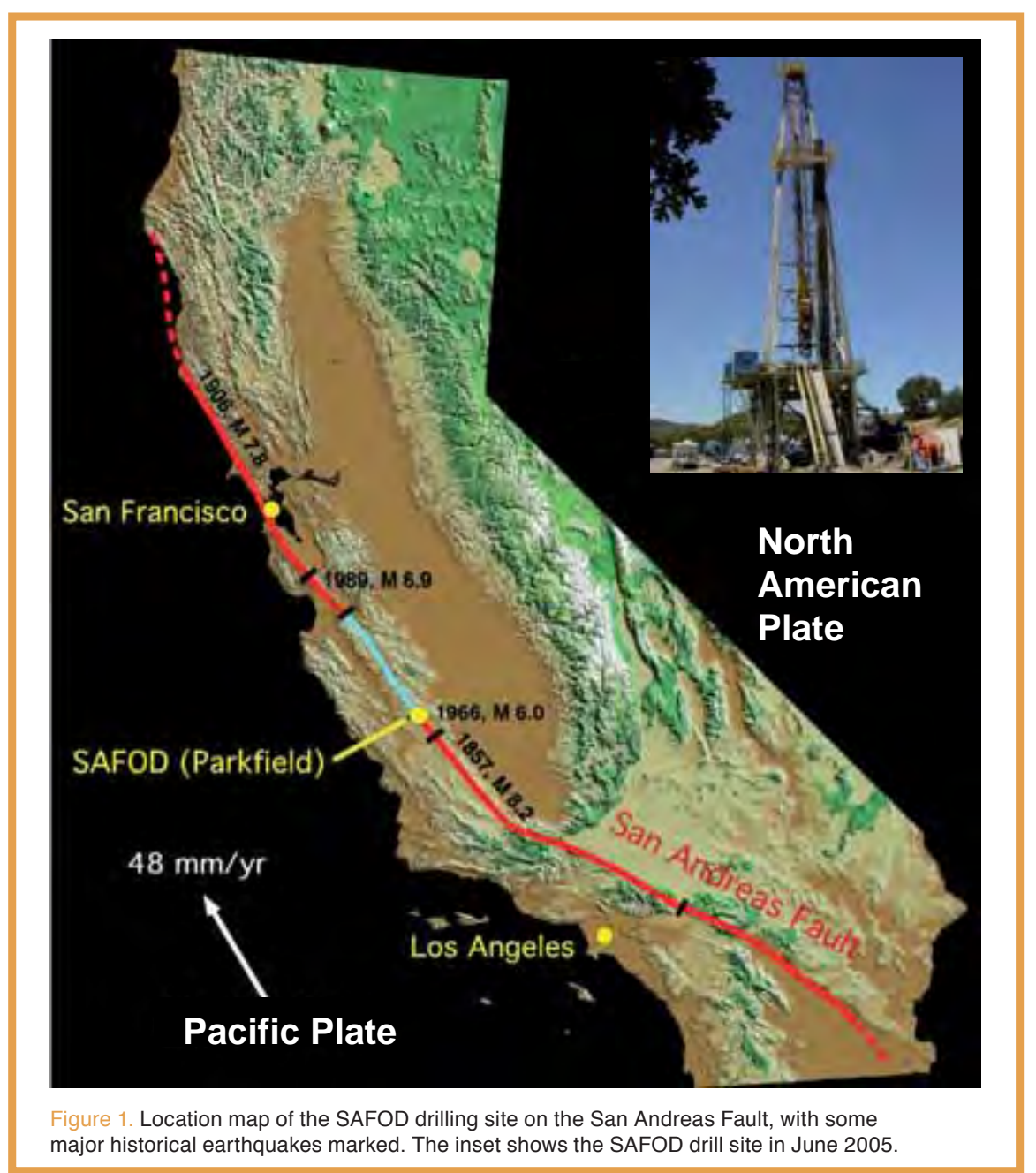

EarthScope is designed to investigate the geological processes that shape the North American continent. The other Earth Scope components, USArray and the Plate Boundary Observatory, are large-scale research efforts focusing on deformation and properties of the Earth's crust in North America (www.earthscope.org).

At the surface, the SAFOD drilling site is located $1.8 \mathrm{~km}$ southwest of the nearly vertical San Andreas Fault such that the inclined borehole passes through the entire fault zone at seismogenic depths (see Fig. 2). Phase 1 of the project was conducted during the summer of 2004 and involved rotary drilling to $2.5-\mathrm{km}$ vertical depth and to within $700 \mathrm{~m}$ of the San Andreas Fault. Phase 2 was conducted during the summer of 2005 and involved rotary drilling through the San Andreas Fault Zone while collecting nearly continuous cuttings, gas samples, and appreciable geophysical logging data, including logging-while-drilling (LWD) data within the San Andreas Fault. Three spot cores were obtained at casing set points during Phases 1 and 2. Rock and fluid samples recovered from the fault zone and country rock are being studied in the laboratory to determine their composition, deformation mechanisms, frictional behavior, and physical properties.

Drilling, sampling, and downhole measurements directly within the San Andreas Fault Zone will substantially advance our understanding of the processes controlling faulting and earthquake generation by providing direct observation on the composition, physical state, and mechanical behavior of a major active fault zone at the depths where earthquakes occur. It will now be possible to measure these processes directly and answer basic questions about earthquake nucleation (including whether some earthquakes are predictable) and rupture propagation. By directly evaluating the roles of fluid pressure, rock friction, chemical reactions, stress, and other parameters during the earthquake process, opportunities will arise to 


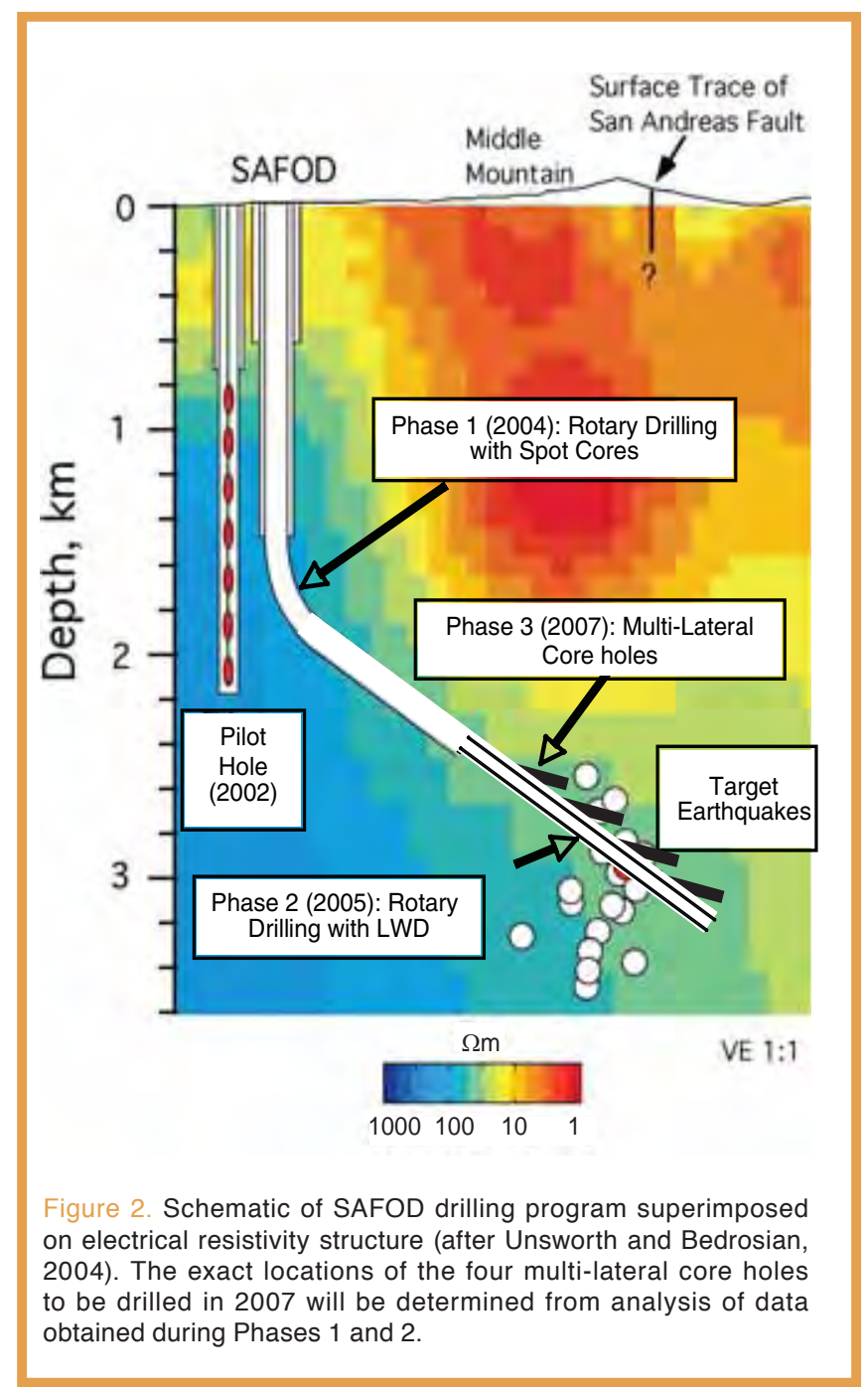

simulate earthquakes in the laboratory and on the computer using representative fault-zone properties and physical conditions.

After considering a number of possible locations along the 1,287-km-long San Andreas Fault, SAFOD scientists agreed upon a unique segment near Parkfield, California, about halfway between Los Angeles and San Francisco (Fig. 1). Parkfield is the most extensively instrumented fault section in the world because of magnitude 6.0 earthquakes that occur in the area every two or three decades, including one on 28 August 2005. SAFOD aims to intersect the fault at 3$\mathrm{km}$ depth in the vicinity of repeating magnitude 2.0 microearthquakes. The locations of microearthquakes and ongoing fault creep detected through repeat measurements of casing shear will be used to select intervals from which to obtain continuous core using sidetracks to the main SAFOD borehole in the summer of 2007, during Phase 3 of the project. This will permit scientists to compare the mineralogy, physical properties, and deformational behavior of fault rocks that fail primarily through creep against those that fail during earthquakes.
Construction of the multi-component SAFOD observatory is well underway, with a three-component seismometer and tiltmeter operating at $\sim 1-\mathrm{km}$ depth in the pilot hole and a fiber-optic laser strainmeter cemented into place behind the casing in the main hole. A number of surface-to-borehole seismic experiments have been performed to characterize seismic velocities and structures at depth, including deployment of an 80-level, 240-component seismic array in SAFOD in the spring of 2005.

With knowledge of $\mathrm{P}$ - and S-wave velocities from the borehole geophysical logs in conjunction with downhole recordings of the SAFOD target earthquake, it appears that the seismically active trace of the fault lies approximately $500 \mathrm{~m}$ southwest of the surface trace, near several candidate zones of particularly anomalous geophysical properties. Following the installation of the casing in the hole in September 2005, observations of casing deformation have apparently pinpointed the exact location of the active fault trace, although this remains to be confirmed by locating microearthquakes using downhole seismic instrumentation located directly within the fault zone.

Scientific results from the Phase 1 and Phase 2 drilling were presented in special sessions at the Fall 2005 American Geophysical Union Meeting in San Francisco. For more information, see the EarthScope Web site (www.earthscope. org), or contact one of the principal investigators Mark Zoback (zoback@pangea.stanford.edu), Stephen Hickman (hickman@usgs.gov) and William Ellsworth (ellsworth@ usgs.gov). Anyone interested in accessing SAFOD data or samples should contact SAFOD data manager Charles Weiland (cweiland@stanford.edu).

\section{References}

Unsworth, M., and Bedrosian, P., 2004. Electrical resistivity at the SAFOD site from magnetotelluric exploration. Geophys. Res. Lett., 31. doi:10.1029/2003GL019405

\section{Author}

Mark D. Zoback, Benjamin M. Page Professor of Earth Sciences and Professor of Geophysics, Department of Geophysics, 397 Panama Mall, Stanford University, Stanford, CA 94305-2215, U.S.A., e-mail: zoback@pangea.stanford. edu

\section{Related Web Links}

http://safod.icdp-online.org http://www.earthscope.org 